\title{
BMJ Open Efficacy of a web-based self-help tool to reduce problem gambling in Switzerland: study protocol of a two- armed randomised controlled trial
}

\author{
Christian Baumgartner (D) , ${ }^{1}$ Elena Bilevicius, ${ }^{2}$ Yasser Khazaal, ${ }^{3,4}$ \\ Sophia Achab (1) , Susanne Schaaf, ${ }^{1}$ Andreas Wenger, ${ }^{1}$ Severin Haug, ${ }^{1}$ \\ Matthew Keough, ${ }^{2}$ David Hodgins, ${ }^{6}$ Michael P Schaub (i) ${ }^{1}$
}

To cite: Baumgartner C, Bilevicius E, Khazaal Y, et al. Efficacy of a webbased self-help tool to reduce problem gambling in Switzerland: study protocol of a two-armed randomised controlled trial. BMJ Open 2019;9:e032110. doi:10.1136/ bmjopen-2019-032110

- Prepublication history for this paper is available online. To view these files, please visit the journal online (http://dx.doi org/10.1136/bmjopen-2019032110).

Received 05 June 2019

Revised 12 November 2019

Accepted 13 November 2019

D Check for updates

(c) Author(s) (or their employer(s)) 2019. Re-use permitted under CC BY-NC. No commercial re-use. See rights and permissions. Published by BMJ.

For numbered affiliations see end of article.

\section{Correspondence to} Christian Baumgartner; christian.baumgartner@isgf. uzh.ch

\section{ABSTRACT}

Introduction The past-year prevalence of problem gambling worldwide averages $2.3 \%$. Switzerland exhibits a slightly lower past-year prevalence rate, of $1.1 \%$, among adults. Only a minority of these adults attend outpatient treatment. Surveyed problem gamblers have explained that they wanted to handle the problem on their own. The option of a web-based self-help programme could potentially reach those users who hesitate to approach treatment centres and help them to reduce or stop their problem gambling. The effectiveness of such web-based interventions has been shown in other countries.

Methods and analysis This two-armed randomised controlled trial (RCT) will examine the efficacy of a webbased self-help intervention, relative to an active control condition with a self-help manual, at reducing problem gambling. The active intervention programme, spanning 8 weeks, consists of nine modules developed to reduce gambling and attenuate psychopathological comorbidity, including depression, anxiety and stress-related disorder symptoms, relying on motivational interviewing and cognitive behavioural therapy. With a target sample size of 352 , questionnaire data will be collected at baseline, and at 8 and 24 weeks after baseline. Primary outcomes will be the number of days one has gambled in the last 30 days. Secondary outcomes will include money and time spent on gambling activities, changes in gamblingrelated problems (Problem Gambling Severity Index, Gambling Symptom Assessment Scale), use of alcohol and cigarettes, and psychopathological comorbidity. All data analysis will comply with the intention-to-treat principle.

Ethics and dissemination The RCT will be conducted in accordance with the Declaration of Helsinki; the consort eHealth Guidelines for studies on medical devices; the European Directive on medical devices 93/42/EEC, Swiss Law and Swiss Regulatory Authority requirements. The study was approved by the ethics committee of the Canton of Zurich. Results will be published in a scientific peerreviewed journal. Participants will be informed via e-mail about study results via a lay-person-friendly summary of trial findings.

Trial registration number Current Controlled Trials registry (ISRCTN16339434).

\section{Strengths and limitations of this study}

- This will be the first study in Switzerland on the effectiveness of a web-based self-help intervention (Win Back Control) to reduce problem gambling.

- This study applies a bolder approach to compare the intervention with an already empirically supported manual as an active control condition and, at the same time, be more ethically sound for people in need compared with using a waitlist control group.

- The developed intervention could bridge the treatment gap and help problem gamblers who otherwise might not seek out traditional mental healthcare.

- One limitation of the current study is the exclusion of gamblers who are currently receiving other treatments to reduce their gambling.

- Another is that, all measurements will be selfreported from the participants and cannot be externally validated.

\section{INTRODUCTION}

Switzerland has a wide array of gambling facilities. There are 21 casinos and about 9000 lottery-vending points, which together raise around SFr1.5 billion yearly. ${ }^{1}$ This makes Switzerland one of the densest countries in the world, in terms of gambling opportunities. ${ }^{2}$ Nevertheless, problem gambling prevalence is comparable or even lower than in other European countries. Recent data indicate a past-year gambling rate of $46.6 \%$, and a problem-gambling prevalence rate of $1.1 \%$ in Switzerland. ${ }^{3}$ In a world-wide report ${ }^{4}$ that assessed problem gambling, depending on the specific country and survey year, the standardised past-year rate of problem gambling was estimated to range from $0.5 \%$ to $7.6 \%$, with an average rate across all countries of $2.3 \%$. There seem to be geographical and cultural differences within Switzerland. Gambling is more pervasive in the French and 
Italian-speaking regions of Switzerland than in Germanspeaking regions. ${ }^{5}$ The inclusion of gambling disorder in the Diagnostic and Statistical Manual of Mental Disorders 5 th Edition (DSM-V $)^{6}$ and the forthcoming International Classification of Diseases Mental and Behavioural Disorders 11th Revision (ICD-11), ${ }^{7}$ as the first behavioural addiction, serves as acknowledgment of gambling as the most distinguishable behavioural addiction. Moreover, this change highlights the need for further treatment options for people who suffer from gambling disorder. Nevertheless, treatments offered in Switzerland ${ }^{8}$ and worldwide remain scarce.

Besides the problems that are inherent to problem gambling (eg, preoccupation with gambling, monetary loss), there is a high rate of psychopathological comorbidity. Seventy-eight per cent of problem gamblers and 95.5\% of pathological gamblers have an additional Diagnostic and Statistical Manual of Mental Disorders 4th Edition (DSM-IV) diagnosis. ${ }^{9}$ Pathological gambling is statistically correlated with an increased risk of developing substance dependencies (OR, 3.9-5.9) ${ }^{10}$ Affective disorders and anxiety disorders are present in $32.7 \%-$ $48.8 \%$ of problematic/pathological gamblers, but only in $6.5 \%-12.3 \%$ of the general population. ${ }^{11}$ Evidence suggests that fewer than $10 \%$ of pathological gamblers are in treatment, ${ }^{12}{ }^{13}$ with the majority seeking treatment only after a significant life crisis. ${ }^{14}$ This, combined with relatively high treatment attrition rates, ranging between $17 \%$ and $76 \%,{ }^{15}{ }^{16}$ suggests that most problem gamblers remain untreated.

Similar international studies have discovered that problem gambling rates among adolescents (age 12-17 years) are typically two to three times those found in adults. ${ }^{17}$ Young adults age 18-24 years also show gambling-related problems to a greater extent than any other adult group. ${ }^{1920}$ Likewise, in Switzerland, in a study ${ }^{21}$ conducted in the French part of the country on a sample of military conscripts (age 18-24 years), the prevalence of problem gambling was $1.4 \%$. In another study conducted in the French part of Switzerland, the prevalence of at-risk gambling was $5.5 \%$ in a sample of adolescents age 14-17 years. ${ }^{22}$ Young people rarely acknowledge problems or look for treatment, despite high rates of problem gambling. ${ }^{23}$ Online tools have the potential to reach and support young adults attempting to deal with gamblingrelated problems, given their familiarity with and preference for the internet, and the anonymity of such tools. ${ }^{24}$ In a similar vein, surveyed adult problem gamblers state that they wanted to 'solve the problem on their own'. ${ }^{25}$ This personal decision should be supported to enhance self-determination capabilities. ${ }^{26}$ Another observation that supports the self-help narrative is that the gambling bans from casinos in Switzerland total 46468 people, ${ }^{1}$ and $>70 \%$ stem from self-exclusion. ${ }^{27}$ Internet interventions operate in a private and anonymous way that respects the gambler's need for autonomy. There is evidence that the internet enables people to be more open and honest, and to offer more accurate self-evaluations regarding their actual problems. ${ }^{28}$ The use of internet-based self-help programmes can even increase professional help-seeking behaviour in gamblers. ${ }^{29}$

Besides these advantages of internet interventions, the cost-effectiveness of these interventions compares favourably to face-to-face interventions. ${ }^{30}{ }^{31}$ Most internet interventions employ a variety of different cognitive behavioural therapy $(\mathrm{CBT})^{32}$ and motivational interviewing ${ }^{33}$ techniques. In one Cochrane report, ${ }^{34} \mathrm{CBT}$ was found to be effective at reducing gambling behaviour and other symptoms of pathological and problem gambling immediately following therapy. Cowlishaw and colleagues $^{34}$ also agree that there is evidence of some benefit from motivational interviewing therapy, in terms of reduced gambling behaviour, though not necessarily the other symptoms of pathological and problem gambling; but they also acknowledge the small numbers of studies in this area. Several internet interventions for problem gambling have implemented these techniques and shown their effectiveness in various countries. ${ }^{35-38}$ These studies document significantly reduced gamblingrelated problems-including anxiety and depressioneven up to 36 months after the intervention ends. ${ }^{36}$

Taken together, currently available data provide evidence that the majority of problem gamblers are not in treatment, even though many of them suffer tremendously from gambling-related problems. A diverse range of treatment options, provided in the least restrictive setting possible, appears most favourable for problematic and pathological gamblers. Web-based self-help offers a promising and cost-effective alternative for problem gamblers who are not yet in treatment or are hesitant to seek face-to-face treatment. Online interventions aim not to replace face-to-face counselling services; nonetheless, they offer an alternative for those who prefer to help themselves and can be used additionally to provide other forms of treatment. The study presented in this protocol seeks to investigate the effectiveness of a web-based selfhelp intervention at reducing problem gambling, while also considering the most frequent psychopathological comorbidity. This is the first study on the efficacy of a webbased tool to reduce problem gambling in Switzerland.

\section{METHODS AND ANALYSIS}

\section{Study design}

The web-based self-help programme Win Back Control will be evaluated with a two-arm randomised controlled trial (RCT), comparing the effectiveness of (1) a web-based self-help intervention and (2) a self-help manual aimed at reducing problem gambling. Blinding is not possible with the applied design. Participants will be unaware of the study hypotheses, but will know if they have been assigned to either the internet intervention or the selfhelp manual, the latter sent by email or downloadable as a PDF file. Any blinding of study personnel is unwarranted, as we will not be directly involved in either the intervention or the assessment. After completing the baseline 


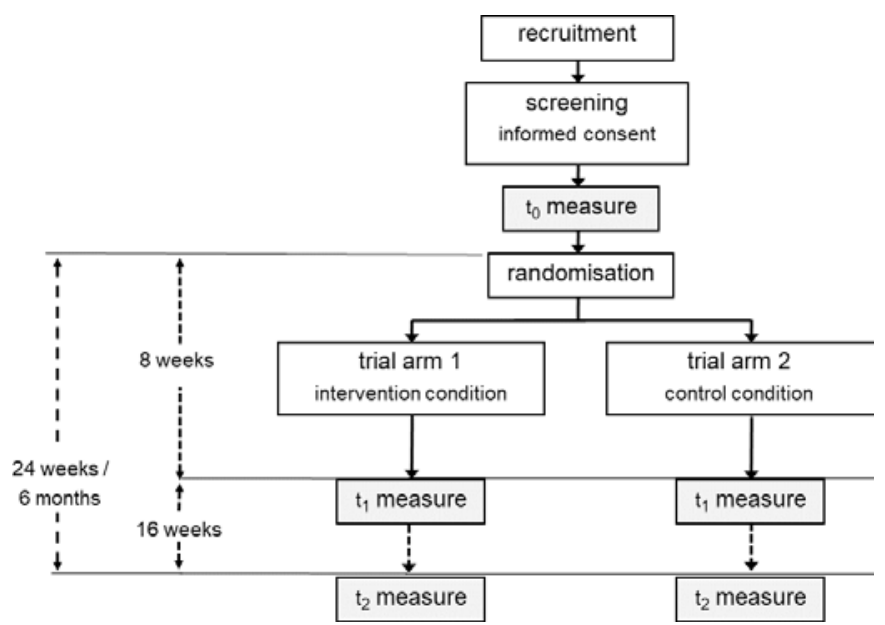

Figure 1 Flowchart of the study based on CONSORT criteria. CONSORT, Consolidated Standards of Reporting Trials.

assessment $\left(\mathrm{t}_{0}\right)$, participants will be randomly allocated to one of the two study arms. Further assessments will take place, both 8 weeks $\left(\mathrm{t}_{1}\right)$ and 24 weeks $\left(\mathrm{t}_{2}\right)$ after baseline (figure 1). The trial has been registered with the ISRCTN registry.

\section{Recruitment of study participants}

Recruitment will take place from March 2019 either until September 2020 or until the target number of 352 participants is reached. Participants will be recruited through the Win Back Control website (winbackcontrol. ch), which is already established and is linked to various internet health portals. Additionally, advertisements will be placed in relevant internet forums and newspapers (or online versions thereof). Depending on the recruitment process, additional ads on Facebook or Google will be placed. The study will mainly recruit people from Switzerland; however, participants from other countries will not be excluded.

All participants who complete the 24-week follow-up assessment will receive either an online voucher of SFr30 or be able to donate that amount to charity.

\section{Registration and consent procedure}

Participants can register online by providing only minimal personal data, including their email address, phone number (for follow-up questionnaires) and basic demographical information (age, gender, level of education, household income).

Informed consent will be accepted once participants have checked several boxes reiterating important study information and submitting their consent by clicking a submission button.

Participants will be assigned to be randomised if deemed eligible, according to the inclusion and exclusion criteria (see table 1 ).

\section{Randomisation and trial flow}

After completing their online baseline assessment, participants will be randomised by the server in a 1:1 ratio into one of two groups.

Participants in the intervention group 1 will receive automated email reminders to login and record their

Table 1 Inclusion and exclusion criteria and underlying rationale

\section{Inclusion criteria}

(1) Informed consent via the web form

(2) Minimal age of 18 years

(3) Gambling activity at least once weekly over the 30 days prior to study entry

(4) A PGSI score $\geq 3$

(5) At least once weekly internet access and a valid email address

(6) Proficiency in German or French

\section{Exclusion criteria}

(1) Self-reported engagement in other outside psychosocial treatments for problem gambling

(2) Last 90-day psychosis or mania

(3) Presence of a severe substance use disorder (DAST score $>5$ or AUDIT score $>20$ )

(4) Elevated suicidality (scoring greater than 'minimal risk' on a screener)

\section{Rationale}

To ensure knowledge of procedures and the declaration of consent

To ensure a minimum age of participation

To ensure that the programme reaches the intended population; increase validity

To ensure that the programme reaches the intended population; increase validity

To ensure at least some access to the intervention

To ensure that participants will be able to understand the information provided

\section{Rationale}

To avoid confounding treatment effects

To avoid having individuals with these problems enter the study

Individuals with a severe substance use disorder need more intensive treatment than provided

To increase safety, participants with elevated suicidality will be referred for face-to-face treatment

AUDIT, Alcohol Use Disorders Identification Test; DAST, Drug Abuse Screening Test; PGSI, Problem Gambling Severity Index. 
gambling activity, money won or lost, and mood in their gambling diary every week.

The two interventions will each last 8 weeks. Follow-up assessments will be 8 and 24 weeks after the start of the programme. As such, there will be a baseline (pretreatment) assessment, an 8-week assessment immediately following the treatment programme, and a final assessment 16 weeks post-treatment (24 weeks postbaseline).

Since subjects will have access to any other online and offline counselling services that are available, they will be asked about their possible use of other treatment services over the course of observation at their final follow-up assessment.

Follow-up assessments will be completed online after a reminder is sent by email to all participants, in which they also will be reminded about the compensation of SFr30. If the final assessment is not completed within 2 days, a reminder will be sent out and another one after 5 days. If these reminders still go unanswered, participants will be contacted by phone roughly 1 week after the third email has been sent and offered a phone interview with study collaborators to complete the follow-up. Should participants still refuse, they will be asked to answer questions about the primary outcomes only or-should they still refuse-to provide a reason for refusing, which will then be documented.

Figure 1 is a flowchart depicting the flow of subjects through the study.

\section{Hypotheses}

We formulated the following detailed study hypotheses with respect to the main outcome: reduction in the number of days of gambling over the last 30 days, comparing the baseline, 8-week and 24-week follow-up assessments:

1. The web-based self-help programme (study arm 1) will be more effective than the self-help manual (study arm 2) at reducing gambling.

Furthermore, we have the following expectations for the secondary outcomes between the baseline, 8-week follow-up and 24-week follow-up assessments:

2. The web-based self-help programme (study arm 1) will be more effective than the self-help manual (study arm 2) at reducing the severity of gambling and gamblingrelated problems, as measured after the 8 weeks of intervention and at 24-week follow-up.

3. The web-based self-help programme (study arm 1) will be more effective than the self-help manual (study arm 2) at reducing symptoms of psychopathological comorbidity, as measured after the 8 weeks of intervention and at 24-week follow-up.

4. The web-based self-help programme (study arm 1) will be more effective than the self-help manual (study arm 2) at reducing alcohol and cigarette use, as measured after the 8 weeks of intervention and at 24-week followup.

5. Participants in study arm 1 will be more satisfied overall with the intervention received than those in study arm 2 after their 8-week intervention.

\section{Intervention}

Win Back Control is an automated web-based self-help tool developed by the Swiss Research Institute for Public Health and Addiction (ISGF, www.isgf.ch) to reduce or stop gambling in problem gamblers. The web-based self-help intervention is comprised of a dashboard, a

W $\overline{\underline{B}}$ C] Diary Modules Help. Profile -

Welcome to Win Back Control

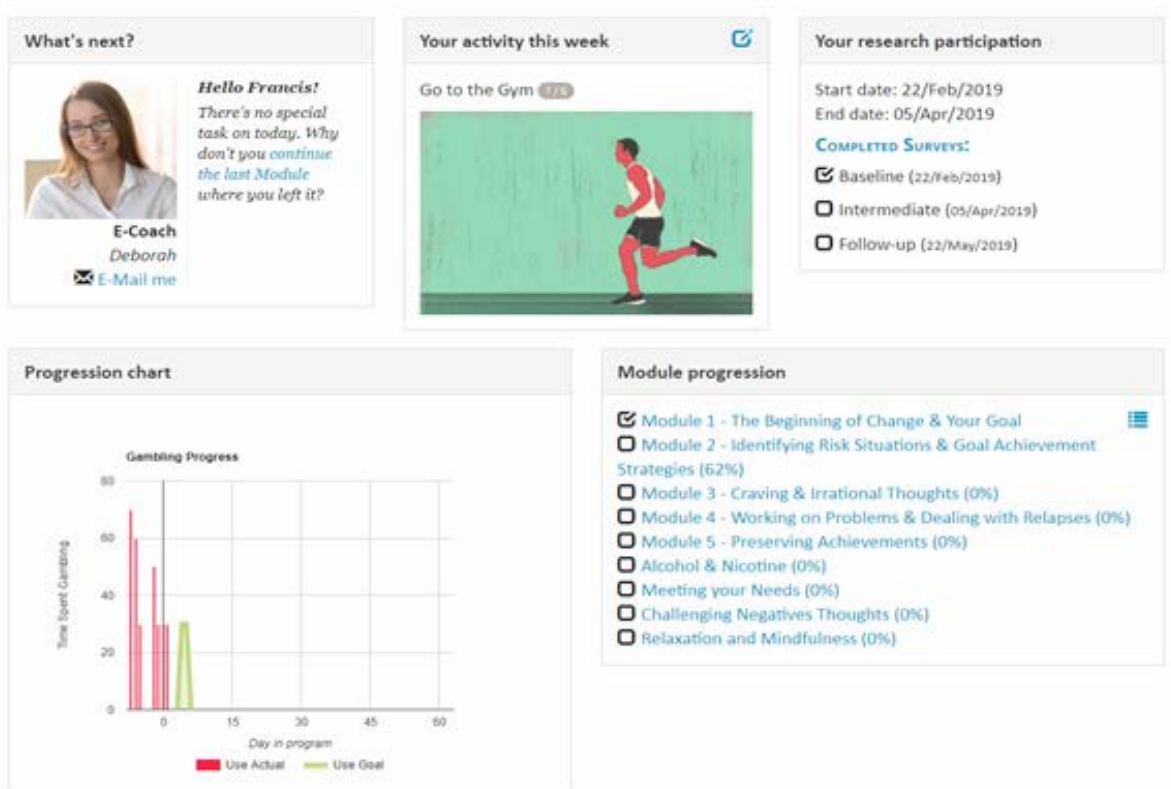

Figure 2 Dashboard in intervention group 1, gives quick overview over the programme progress. 
gambling diary and nine modules that were designed to reduce gambling, relying on the principles of motivational interviewing, ${ }^{33}$ self-control practices and cognitive behavioural therapy. ${ }^{32}$ The modules stem from previously developed web-based interventions for cannabis and alcohol use ${ }^{3940}$ developed by the ISGF, and on the self-help manual 'Becoming a Winner', which was written by Hodgins and Makarchuk. ${ }^{41}$ The core modules (1-5) must be completed in their intended sequence, meaning that finishing each core module unlocks access to the next one. The complimentary modules are designed to address common comorbidity (substance use, anxiety disorders and depression) that are present in some problem gamblers but not all. Complimentary modules will be shown and recommended based on the baseline evaluation, which should reduce the intervention's complexity. Participants will be encouraged to repeat any modules they feel they need or that they perceive as helpful. Since Win Back Control is considered a medical device, according to EU guidelines 93/42/EWG and 2007/47/EWG, its conformity has been assessed and potential risks have been evaluated. It is now fully Conformité Européenne (CE) certified. The CE certification includes technical documentation (software release, test protocols, software requirements), clinical evaluation and a risk management plan. The following elements of Win Back Control will be used in study arm 1.

\section{Dashboard}

The central hub is the dashboard, designed to provide useful information at a quick glance. The dashboard displays the dates of the two follow-up assessments and indicates when they have been completed. The same holds for the individual intervention modules, which, when the corresponding icons are clicked on, will lead participants to the page in the module where they left off, the last time they worked on it. There also is a way for participants to enter gambling data directly from the last 2 weeks, so that a progress graph is displayed. Another feature is an activity planner that lets participants plan an activity for the current week, upload a picture and rate the level of enjoyment they anticipate having prior to the activity, and the level of enjoyment they actually experienced, as rated once they have finished it.

Figure 2 shows the dashboard implemented in the intervention group 1.

\section{Self-help intervention modules}

There are a total of nine self-help intervention modules, which are depicted on the intervention website's module overview page (see figure 3), as well as on the dashboard. A short summary of module content is provided in table 2. Participants are encouraged to complete one of the core modules (1-5) each week. As stated earlier, the core modules must be completed in their intended sequence, though users are encouraged to repeat any modules they choose. A red bar in the module-overview indicates any progress they have made within each module; that bar turns green once a user has completed the entire module. The user will be encouraged to complete as many modules as possible.

\section{Gambling diary}

Participants will be encouraged to completely fill out their gambling diary on no less than a weekly basis. There, they will be asked to record their goal about how much they

\section{W $\overline{\text { B }}$ C Diary Modules Help. Proflie.}

\section{Module overview}

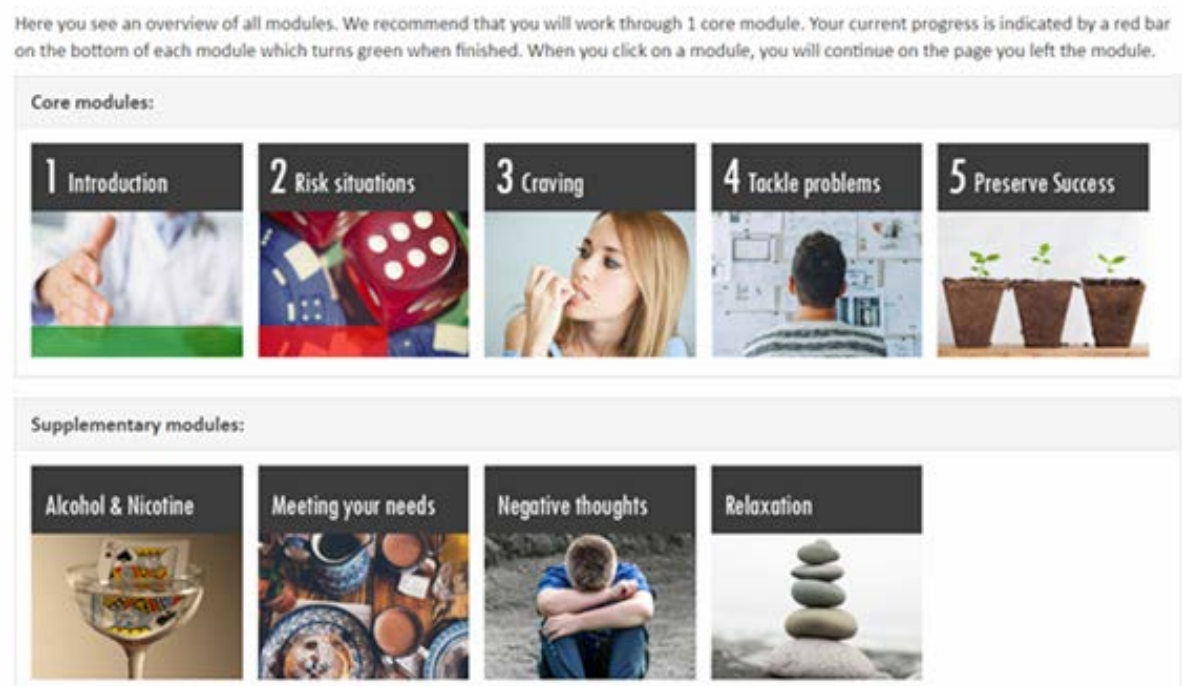

Figure 3 Module overview in intervention group 1, separated in core and supplementary modules. 
Table 2 Modules

\begin{tabular}{|c|c|}
\hline Module & Content \\
\hline Module 1: the beginning of change and your goal & $\begin{array}{l}\text { General overview. } \\
\text { Introduction to fictional companions. } \\
\text { Reflections on personal gambling. } \\
\text { Setting a personal reduction goal. }\end{array}$ \\
\hline $\begin{array}{l}\text { Module } 2 \text { : identifying risk situations and goal-achievement } \\
\text { strategies }\end{array}$ & $\begin{array}{l}\text { Identifying personal high-risk situations. } \\
\text { Recognising seemingly irrelevant, but triggering decisions. } \\
\text { Strategies to change gambling habits. } \\
\text { Resisting gambling in specific situations (eg, situations } \\
\text { involving negative emotions). } \\
\text { Developing personal strategies to reduce/abstain from } \\
\text { gambling. }\end{array}$ \\
\hline Module 3: craving and irrational thoughts & $\begin{array}{l}\text { Concept of craving. } \\
\text { Ways to deal with feelings of craving. } \\
\text { Learning about irrational thoughts that lead to more frequent } \\
\text { and longer gambling, and how to defuse these irrational } \\
\text { thoughts. }\end{array}$ \\
\hline Module 5: preserving achievements & $\begin{array}{l}\text { Review of programme. } \\
\text { List of five personalised points to help secure achievements } \\
\text { after the programme is complete. }\end{array}$ \\
\hline Module E1: alcohol and nicotine & $\begin{array}{l}\text { Discuss connection between gambling and alcohol and } \\
\text { nicotine. } \\
\text { Tips and strategies to drink and smoke less. }\end{array}$ \\
\hline Module E4: relaxation and mindfulness & $\begin{array}{l}\text { Simple introduction to the concept of mindfulness. } \\
\text { Progressive muscle relaxation. } \\
\text { Imagination exercises. }\end{array}$ \\
\hline
\end{tabular}

want to gamble over upcoming days and how much they actually gambled in past days (in minutes). Additionally, they can enter how much money they won or lost and their mood on each specific day. A graph is generated live with these data inputs, providing the user with visual feedback. The ability to anonymously set daily gambling goals could strengthen the self-efficacy of users. The potential to track their own wins and losses will counteract the selective memory, often exhibited by gamblers, which recalls large wins but has difficulty recalling losses. ${ }^{42}$ Mood tracking will encourage introspection and will help each user see the connection between their emotions and their gambling. Figure 4 shows a 2 -week sample diary.

Normative feedback

After each finished assessment, users will be shown a page that gives them feedback, based on how they scored on specific questionnaires. This feedback should give them a better understanding of their current situation and increase the usefulness of the assessment to them, thereby ideally enhancing follow-up rates. It also gives the user specific recommendations about which modules could be particularly helpful to them. Figure 5 presents one example of the normative feedback presented after completing the baseline assessment.

\section{Control condition}

We will use an active control condition, as there has been concern of overestimating treatment effects when employing a waiting list control design, ${ }^{43}$ as well as it being more ethical to provide actual immediate help to addicts. Those in the active control group will receive a copy of the self-help manual 'Becoming a Winner: Defeating Problem Gambling', written by Hodgins and 
Woche 2

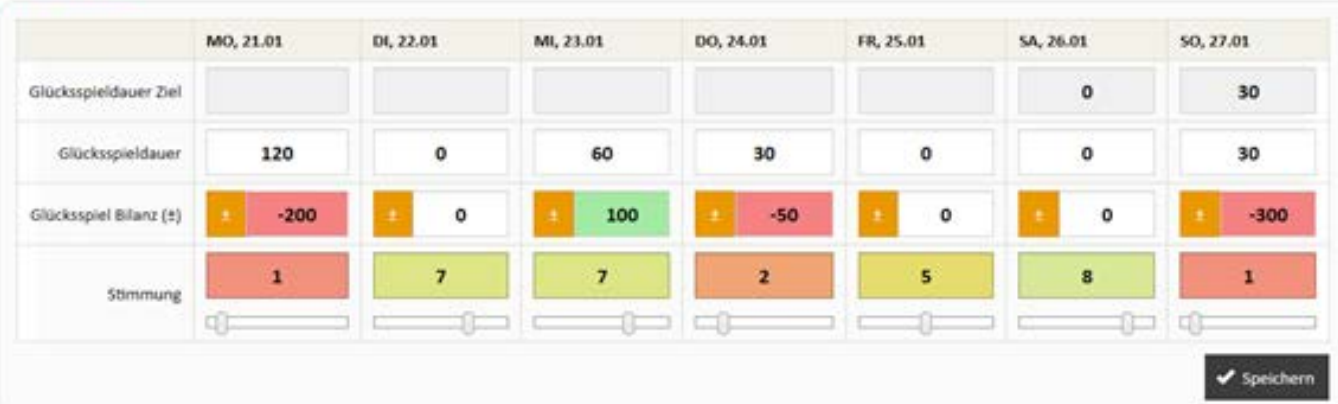

Woche 1

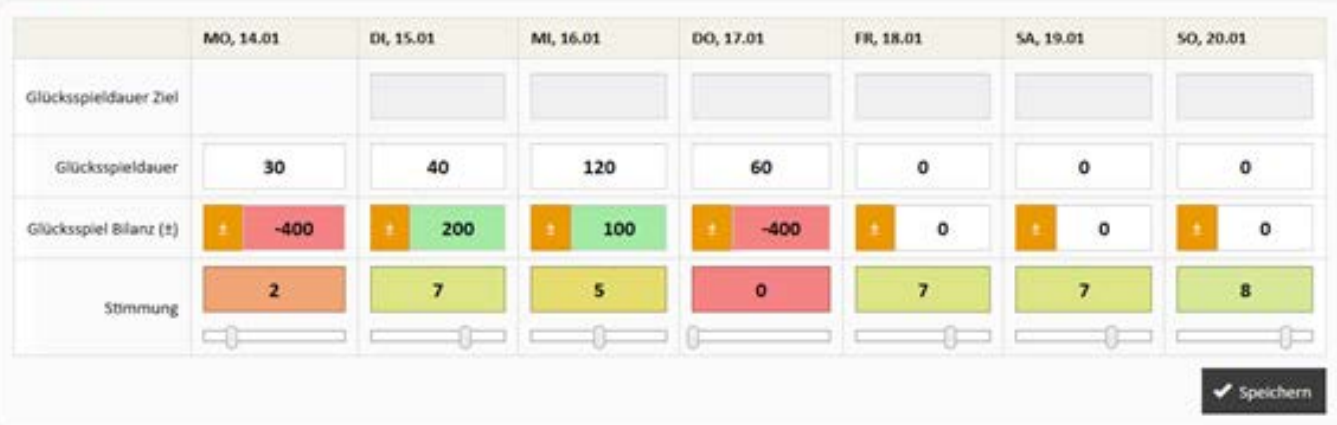

Figure 4 A 2-week sample of the gambling diary used in intervention group 1.

Makarchuk, ${ }^{41}$ via the website and by email. The manual was translated into German and French and adapted to fit the gambling opportunities in Switzerland. The efficacy of this manual has been documented in several studies. ${ }^{44}$ At the last follow-up assessment, participants will be asked if, over the course of their 24 weeks in the study, they used other treatments and what they were; these data will then be analysed.

\section{Measurements}

Sociodemographic data will include sex, age and level of education. Table 3 provides an overview of and schedule for the assessment tools that will be employed.

\section{Primary outcome}

The primary outcome of interest will be the number of days of gambling over the last 30 days.

\section{Secondary outcomes}

Money lost over the last 30 days and time gambling in the last 7 days will be rated via the Timeline Follow-Back (TLFB) method. ${ }^{46}$

The Problem Gambling Severity Index (PGSI) contains nine-items that assess a broad array of problems experienced by individuals who engage in problem gambling (eg, feelings of guilt, financial problems and so on). ${ }^{47}$ The PGSI is the most widely used self-report measure of gambling harms in the literature. The total PGSI score will be used in this study to capture changes in gambling harms following intervention.

The Gambling Symptom Assessment Scale (G-SAS) is a 12-item self-report questionnaire that was designed specifically to capture changes in gambling symptoms following treatment. ${ }^{48}$ The main advantage of using the G-SAS as a secondary measure of gambling symptom change is that it includes several questions about gambling urges.

Alcohol and cigarette use will be assessed using the TLFB method. ${ }^{46}$

The Patient Health Questionnaire-9 is a reliable and validated, 9-question tool developed to assess an individual's degree of depression. ${ }^{49}$ With a total score of 27 , a score of 10 or higher is a considered a good indication of a major depressive disorder. ${ }^{50}$

The Generalised Anxiety Disorder 7 (GAD-7) is a 7-item, self-report questionnaire to screen for and estimate the severity of generalised anxiety disorder, and has good reliability as well as factorial and concurrent validity. ${ }^{51}$ Its items ask about nervousness, inability to stop worrying, excessive worry, restlessness, difficulty relaxing, easy irritation and the fear of something awful happening. Total scores range from 0 to 21, with a recommended threshold at which GAD is considered likely of 10 .

The six-item short version of the ADHD Self-Report Scale$V 1.1$ can be self-administered easily and quickly. ${ }^{52}$ With a total possible score of 24 and a cut-off score of 14, this sixitem version has been shown to have strong concordance with clinician diagnoses, while being significantly shorter than the full 18-item version.

The short screening scale for DSM-IV posttraumatic stress disorder (PTSD-7) is designed to assess for a lifetime history of PTSD. ${ }^{53}$ A score of 4 or more on the sevensymptom screening scale suggests PTSD. The National 

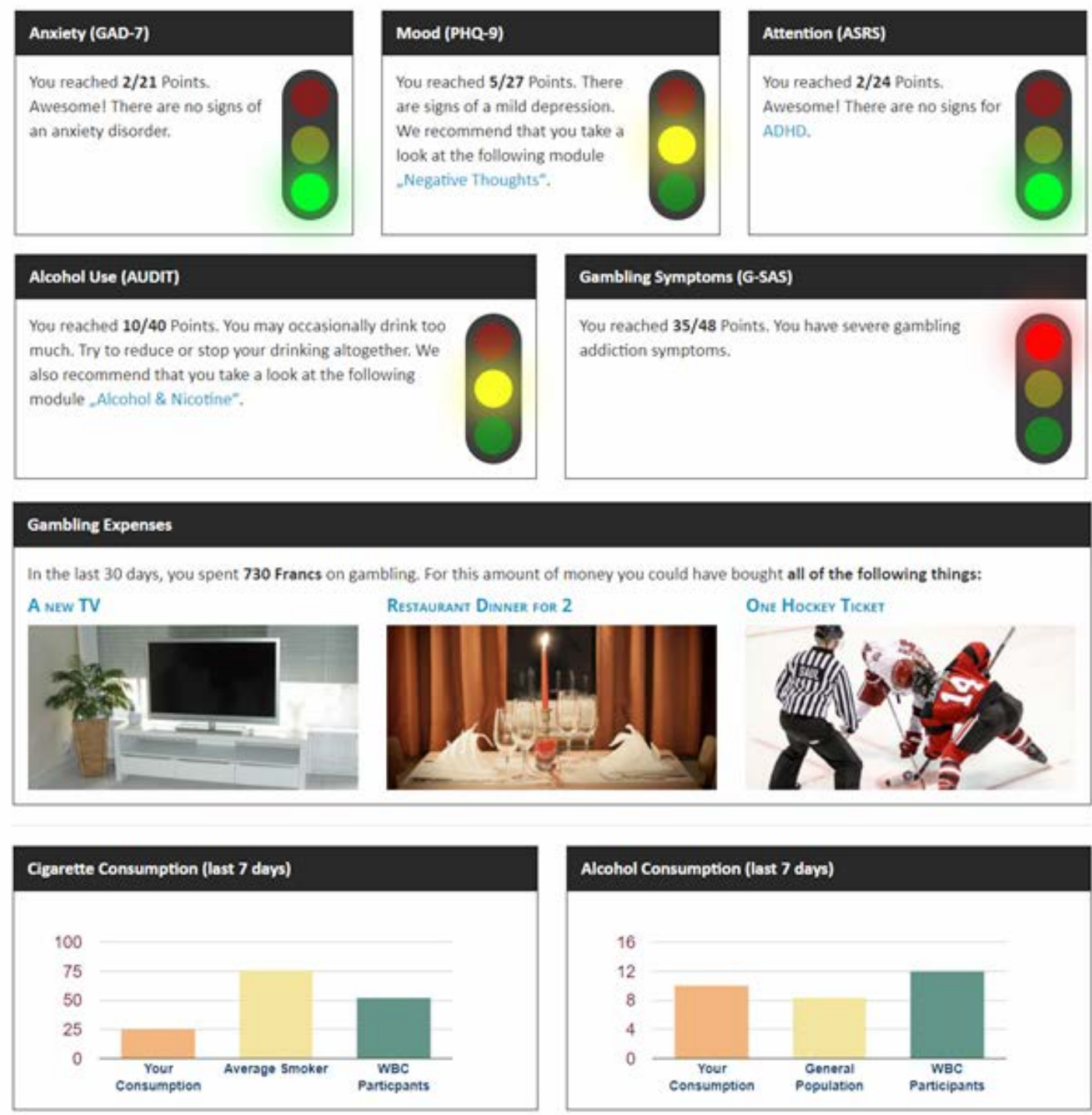
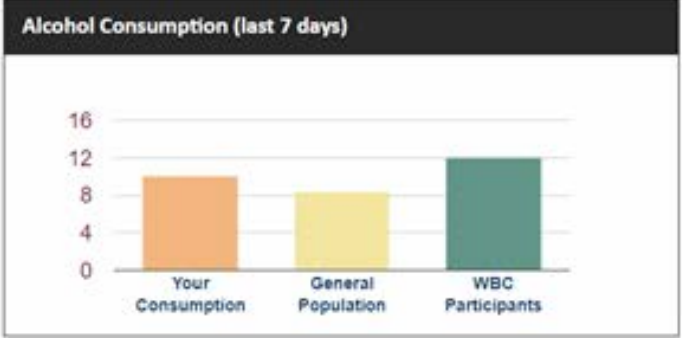

Figure 5 A personalised normative feedback based on the user's questionnaires data and norms.

Comorbidity Study Replication ${ }^{10}$ showed that $14.8 \%$ of lifetime problem gambler also met the criteria for lifetime PTSD.

The Monetary Choice Questionnaire (MCQ) will be used to assess delay discounting, ${ }^{54}$ which has consistently been linked to addictive disorder treatment response. ${ }^{55}$ The MCQ is a widely used and extensively validated measure of discounting. Individuals make 27 choices between smaller, immediate rewards and larger delayed rewards, which are preconfigured at various levels of hyperbolic discounting.

The Alcohol Use Disorders Identification Test (AUDIT) ${ }^{56}$ and the Drug Abuse Screening Test (DAST-10) ${ }^{57}$ are both widely used questionnaires. They will be used to screen for the exclusion criterion of a severe substance use disorder.

The use of drugs besides alcohol and cigarettes will be assessed using the National Institute on Drug Abuse Screening tool (NIDA ASSIST). ${ }^{58}$ Some examples of these additional substances include cannabis, cocaine, prescription medication, methamphetamines and opioids.
The P4-Sreener ${ }^{59}$ is a brief 4 -item measure to assess potential suicide risk. If an elevated risk of suicide (scoring greater than 'minimal risk') is recognised at any of the three assessments, the study participant will be advised to call an emergency number and/or visit any local facility listed in a prepared list.

The Client Satisfaction Questionnaire, adapted to internetbased interventions (CSQ-I), has been shown to be a suitable measure, from the user's perspective, for evaluating web-based health interventions. It is scored easily by summing up the individual item scores to produce a score ranging from 8 to 32 , with higher scores indicating greater satisfaction. $^{60}$

Furthermore, the occurrence of any negative effects will be identified, as in Rozental et al, at the 24-week follow-up assessment. $^{61}$

Participants in the control group will be asked if they have used the provided manual and to which extent, at the 24-week follow-up assessment. 
Table 3 Schedule for the assessment instruments

\begin{tabular}{llll}
\hline & $\begin{array}{l}\text { Baseline } \\
\text { Assessment instruments }\end{array}$ & $\begin{array}{l}\mathbf{8} \text { weeks } \\
\left(\mathbf{t}_{\mathbf{0}}\right)\end{array}$ & $\begin{array}{l}\mathbf{2 4} \text { weeks } \\
\left(\mathbf{t}_{\mathbf{2}}\right)\end{array}$ \\
\hline $\begin{array}{l}\text { 1. Sociodemographics } \\
\text { 2. Timeline Follow back }\end{array}$ & $\mathrm{X}$ & $\mathrm{X}$ & $\mathrm{X}$ \\
$\begin{array}{l}\text { for Gambling, Smoking } \\
\text { and Alcohol }\end{array}$ & & &
\end{tabular}

$\begin{array}{lll}\text { 3. Patient Health } & X & X \\ \text { Questionnaire for } & & \\ \text { Depression (PHQ-9) } & & \text { X } \\ \text { 4. Generalised Anxiety } & \text { X } \\ \text { Disorder Screener (GAD- } & & \\ \text { 7) } & \end{array}$

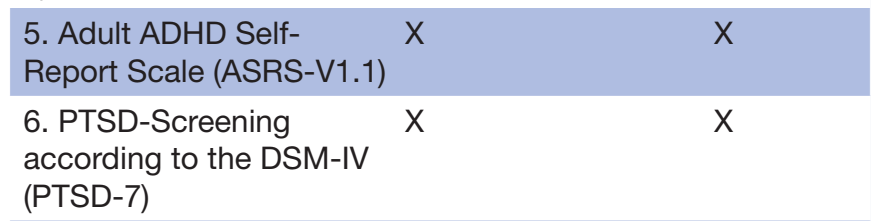

$\begin{array}{llll}\begin{array}{l}\text { 7. Problem Gambling } \\ \text { Severity Index (PGSI) }\end{array} & \text { X } & \text { X } & \text { X } \\ \text { 8. Gambling Symptom } & \text { X } & \text { X } & \text { X } \\ \text { Assessment Scale (G- } & & & \\ \text { SAS) } & & & \end{array}$

\begin{tabular}{l}
$\begin{array}{l}\text { 9. Monetary Choice } \\
\text { Questionnaire (MCQ) }\end{array}$ \\
$\begin{array}{l}\text { 10. Alcohol Use Disorders } \\
\text { Identification Test (AUDIT) }\end{array}$ \\
$\begin{array}{l}\text { 11. National Institute on } \\
\text { Drug Abuse Screening } \\
\text { (NIDA ASSIST) }\end{array}$ \\
$\begin{array}{l}\text { 12. Drug Abuse Screening X } \\
\text { Test (DAST-10) }\end{array}$ \\
$\begin{array}{l}\text { 13. Suicidality Screener } \\
\text { (P4-SCR) }\end{array}$ \\
$\begin{array}{l}\text { 14. Client Satisfaction } \\
\text { Questionnaire for }\end{array}$ \\
Interventions (CSQ-I) \\
$\begin{array}{l}\text { 15. Negative effects } \\
\text { according to Rozental }\end{array}$ \\
\hline
\end{tabular}

Lastly, we will ask all participants if they have used any treatment other than Win Back Control or Becoming a Winner during the 24 weeks and, if so, to select from a predefined list of services.

As an indicator of treatment adherence, data will be collected on how many modules have been completed by each participant. Treatment retention will be measured as the number of weeks during which the gambling diary was filled out and the last login over the 8-week period.

\section{Sample size calculation}

Anticipating that a Cohen's d of 0.30, based on our previous study experience, ${ }^{39}$ will be realistic for the effectsize differences between the defined main outcome of the web-based tool and the manual, a sample size of $n=176$ in each study group would have $80 \%$ power, based on calculations performed with $\mathrm{G}^{*}$ Power software, with an alpha error of $5 \%$ and two-tailed testing. Thus, we aim to recruit a total of 352 participants. Adjusting for drop-outs is not deemed necessary, as missing data will be imputed.

\section{Data analyses}

Data will be analysed according to the intention-to-treat (ITT) principle. To address missing data for the ITT analyses, we will apply multiple imputation procedures with the package $\mathrm{MICE}^{61}$ in $\mathrm{R}$ ( $\mathrm{R}$ Foundation for Statistical Computing, Vienna). MICE involves specifying a multivariate distribution for the missing data, and drawing imputations from their conditional distributions by Markov chain Monte Carlo techniques. We plan to use 20 imputed data sets, as deemed sufficient by Buuren and Groothuis-Oudshoorn. ${ }^{62}$

The imputation model will include all primary and secondary outcome variables. Adjunct variables, like demographic data, may be included if they improve convergence of the imputation model.

We will test for differences in primary and secondary continuous outcome variables between the two study arms at baseline and the follow-up points using linear mixed models (LMMs). The LMMs will be specified to model clusters and repeated measures by defining random effects for study condition and time (repeated measures). Appropriate distributions for non-normal continuous outcomes will be specified (eg, negative binomial, zero-inflated).

\section{Data security}

The intervention was programmed and developed with the Content Management System Drupal 7 which uses a MySQL-Database. The intervention will be maintained by the computer programmers at the ISGF. All connections are encrypted and password-protected through a SSL protocol. Each user will have only see his/her own information. The final data will be exported from the database. For the data analysis, the data will be stored on local computers at the PI's institution.

Email address and phone number will be deleted after the study is completed.

\section{Patient and public involvement}

The current intervention was evaluated by former problem gamblers and gambling experts. They made key inputs regarding content, presentation and wording of the programme. There was no patient and public involvement in the study design, hypotheses, outcome measures or recruitment. Participants will be informed via email about study results via a lay-person-friendly summary of trial findings, if they have requested so at the time of registration.

\section{ETHICS AND DISSEMINATION}

The study will be conducted in accordance with the ethics board-approved protocol and the principles stated in the 
current version of the Declaration of Helsinki; the consort eHealth Guidelines ${ }^{63}$ for studies on medical devices; the European Directive on medical devices 93/42/EEC; and the ISO Norm 14155 and ISO 14971, Swiss Law and Swiss Regulatory Authority requirements. The CEC and regulatory authorities will receive annual safety and interim reports and be informed about study termination, in agreement with local requirements.

Results will be published in a scientific peer-reviewed journal.

\section{DISCUSSION}

Several published studies have documented the effectiveness of internet-delivered interventions for problem gambling. ${ }^{35-38}$ Only one of the programmes ${ }^{38}$ was a standalone intervention; however, the others were accompanied by weekly (although short) telephone support. Two of the programmes did not apply a control condition $^{3637}$; one compared the effects of the intervention with a waiting list $^{35}$; and one compared the programme to brief normative feedback. ${ }^{38}$ The currently proposed study applies a bolder approach to compare the intervention with an already empirically supported manual ${ }^{45}$ as an active control condition. The current design will provide insights into how and if the presentation of information influences the recovery process of gamblers; yet, at the same time, be more ethically sound for people in need. The results of this RCT will show if a web-based self-help tool could help problem gamblers in Switzerland. After this evaluation, if found to be effective, the programme will be rendered freely available for public health, and translated into Italian.

\section{Limitations}

The following study limitations must be considered:

First, gamblers who are currently receiving other treatments to reduce their gambling will be excluded. However, Win Back Control was designed to reach gamblers whofor personal or practical reasons-would not attend traditional addiction counselling. Second, all measurements will be self-reported. Third, as found with our previous web-based intervention, ${ }^{38}$ we expect relatively high rates of dropout from both treatment arms. Lastly, another possible limitation of web-based studies is the potential for reduced adherence rates, due to the distant nature of the intervention.

\footnotetext{
Author affiliations

${ }^{1}$ Swiss Research Institute for Public Health and Addiction, University of Zurich, Zurich, Switzerland

${ }^{2}$ Department of Psychology, University of Manitoba, Winnipeg, Manitoba, Canada ${ }^{3}$ Addiction Medicine, Department of Psychiatry, University Hospital of Lausanne, Lausanne, Switzerland

${ }^{4}$ Research Centre, Institute of Mental Health, University of Montreal, Montreal, Quebec, Canada

${ }^{5}$ WHO Collaborating Centre for Training and Research in Mental Health, University of Geneva, Geneva, Switzerland

${ }^{6}$ Department of Psychology, University of Calgary, Calgary, Alberta, Canada
}

Acknowledgements We would like to thank the Spielen ohne Sucht, the Zentrum für Spielsucht and the Groupement Romand d'Etudes des Addictions for helping to conduct the study.

Contributors MPS set up the initial idea and plan for this study. CB did the first draft of the paper and prepared the final manuscript. CB, MPS and SS developed the intervention of study arm 1 . Study arm 2 was developed by $\mathrm{DH}$ and adapted to Switzerland by $\mathrm{CB}, \mathrm{YK}$ and $\mathrm{SA}$. AW and CB programmed and implemented the study websites of Win Back Control. EB, YK, SA, SH, MK and DH helped throughout the development of the interventions and gave valuable feedback to the present study protocol. All authors approved the final version of the manuscript submitted for publication. $\mathrm{CB}$ is the guarantor.

Funding This project is cofinanced by the 16 SOS-Spielsucht-Cantons, Health Promotion Switzerland and the Canton of Zurich. The funders had and will have no role in study design, analysis, decision to publish or preparation of manuscripts.

Competing interests None declared.

Patient consent for publication Not required.

Ethics approval The study was approved by the ethics committee of the Canton of Zurich on 18 December 2018 (BASEC-Nr. 2018-01989).

Provenance and peer review Not commissioned; externally peer reviewed.

Open access This is an open access article distributed in accordance with the Creative Commons Attribution Non Commercial (CC BY-NC 4.0) license, which permits others to distribute, remix, adapt, build upon this work non-commercially, and license their derivative works on different terms, provided the original work is properly cited, appropriate credit is given, any changes made indicated, and the use is non-commercial. See: http://creativecommons.org/licenses/by-nc/4.0/.

\section{ORCID iDs}

Christian Baumgartner http://orcid.org/0000-0002-5570-7607

Sophia Achab http://orcid.org/0000-0002-3861-3297

Michael P Schaub http://orcid.org/0000-0002-8375-4005

\section{REFERENCES}

1 Swiss Federal Gaming Board (2016). Jahresbericht der Eidgenössischen Spielbankenkommission 2015 [2015 Federal gambling board annual report]. Available: http://www.esbk.admin.ch/ dam/data/esbk/publiservice/jb/jahresbericht_2015-d.pdf

2 Carlevaro T, Lischer S, Sani A-M, et al. The inclusion of health concerns in Swiss gambling legislation: an opportunity to access industry data. Int Gambl Stud 2017;17:251-8.

3 Eichenberger Y, Rihs-Middel M. Glücksspiel: Verhalten und Problematik in Der Schweiz. Institut Ferarihs, 2014.

4 Williams RJ, Volberg RA, Stevens RM. The population prevalence of problem gambling: methodological influences, standardized rates, jurisdictional differences, and worldwide trends Ontario Problem Gambling Research Centre; 2012.

5 Luder M-T, Berchtold A, Akré C, et al. Do youths gamble? you BET! a Swiss population-based study. Swiss Med Wkly 2010;140:w13074.

6 American Psychiatric Pub. Diagnostic and statistical manual of mental disorders (DSM-5®)2013.

7 World Health Organization. International statistical classification of diseases and related health problems (11th revision), 2018. Available: https://icd.who.int/browse11/l-m/en

8 Billieux J, Achab S, Savary J-F, et al. Gambling and problem gambling in Switzerland. Addiction 2016;111:1677-83.

9 Meyer C, Rumpf H-J, Kreuzer A, et al. Pathologisches Glücksspielen und Epidemiologie (page): Entstehung, Komorbidität, remission und Behandlung. Endbericht an Das Hessische Ministerium Des Innern Und Für Sport 2011.

10 Kessler RC, Hwang I, LaBrie R, et al. Dsm-Iv pathological gambling in the National comorbidity survey replication. Psychol Med 2008;38:1351-60.

11 Bischof A, Meyer C, Bischof G, et al. Comorbid axis I-disorders among subjects with pathological, problem, or at-risk gambling recruited from the general population in Germany: results of the page study. Psychiatry Res 2013;210:1065-70.

12 Cunningham JA. Little use of treatment among problem gamblers. Psychiatric Services 2005;56:1024-a-5.

13 Slutske WS, Blaszczynski A, Martin NG. Sex differences in the rates of recovery, treatment-seeking, and natural recovery in pathological gambling: results from an Australian community-based twin survey. Twin Res Hum Genet 2009;12:425-32. 
14 Clarke D, Abbott M, DeSouza R, et al. An overview of help seeking by problem gamblers and their families including barriers to and relevance of services. Int J Ment Health Addict 2007;5:292-306.

15 Ladouceur R, Sylvain C, Boutin C, et al. Cognitive treatment of pathological gambling. J Nerv Ment Dis 2001;189:774-80.

16 Westphal J. Attrition among gambling treatment patients: clinical and research implications. In: International gambling conference. Auckland, New Zealand, 2006.

17 Delfabbro P, Thrupp L. The social determinants of youth gambling in South Australian adolescents. J Adolesc 2003;26:313-30.

18 Dickson L, Derevensky JL, Gupta R. Youth gambling problems: examining risk and protective factors. Int Gamb/ Stud 2008;8:25-47.

19 Derevensky J. Foreword. In: Meyer G, Hayer T, Griffiths M, eds. Problem gambling in Europe. New York: Springer, 2009.

20 Productivity Commission. Gambling: final report. Australia: Canberra, 2010.

21 Tomei A, Tichelli E, Ewering N, et al. A descriptive study of gambling among emerging adult males in French-speaking Switzerland. J Gambl Stud 2015;31:607-20.

22 Tozzi L, Akre C, Fleury-Schubert A, et al. Gambling among Youths in Switzerland and its association with other addictive behaviours. A population-based study. Swiss Med Wkly 2013;143:w13768.

23 Hardoon KK, Gupta R, Derevensky JL. Psychosocial variables associated with adolescent gambling. Psychol Addict Behav 2004;18:170-9.

24 Monaghan S, Wood RTA. Internet-Based interventions for youth dealing with gambling problems. Int $J$ Adolesc Med Health 2010;22:113.

25 Hing N, Nuske E, Gainsbury S. Gamblers at-risk and their helpseeking behaviour. Melbourne: Gambling Research Australia, 2012.

26 Khazaal Y, Monney G, Richter F, et al. « Jeu-contrôle », rationnel d'une application de soutien aux limites de jeux. Journal de Thérapie Comportementale et Cognitive 2017;27:129-37.

27 Thompson W. Public integrity in Casino gambling: the Swiss social concept. Public Integrity 2007;9:377-88.

28 Fullwood C, Sheehan N, Nicholls W. Blog function revisited: a content analysis of MySpace blogs. Cyberpsychol Behav 2009;12:685-9.

29 Cooper G. Exploring and understanding online assistance for problem gamblers: the pathways disclosure model. Int J Ment Health Ad 2004;1:32-8.

30 Klein B, Richards JC, Austin DW. Efficacy of Internet therapy for panic disorder. J Behav Ther Exp Psychiatry 2006;37:213-38.

31 Riper H, Kramer J, Conijn B, et al. Web-Based self help interventions for problem drinkers and their offspring. Improving Public Health through the Internet 2006.

32 Meichenbaum D. Cognitive-Behavior modification: an integrative approach. , 1977: 6, 185-92.

33 Rollnick S, Miller WR. What is motivational interviewing? Behav Cogn Psychother 1995;23:325-34

34 Cowlishaw S, Merkouris S, Dowling N, et al. Psychological therapies for pathological and problem gambling. Cochrane Database Syst Rev 2012;39.

35 Castrén S, Pankakoski M, Tamminen M, et al. Internet-Based CBT intervention for gamblers in Finland: experiences from the field. Scand J Psychol 2013;54:230-5.

36 Carlbring P, Degerman N, Jonsson J, et al. Internet-Based treatment of pathological gambling with a three-year follow-up. Cogn Behav Ther 2012;41:321-34.

37 Myrseth H, Brunborg GS, Eidem M, et al. Description and pre-post evaluation of a telephone and Internet based treatment programme for pathological gambling in Norway: a pilot study. Int Gambl Stud 2013;13:205-20.

38 Hodgins DC, Cunningham JA, Murray R, et al. Online Self-Directed interventions for gambling disorder: randomized controlled trial. J Gambl Stud 2019;35:635-51.

39 Schaub MP, Haug S, Wenger A, et al. Can reduce--the effects of chat-counseling and web-based self-help, web-based selfhelp alone and a waiting list control program on cannabis use in problematic cannabis users: a randomized controlled trial. BMC Psychiatry 2013;13:305.
40 Schaub MP, Blankers M, Lehr D, et al. Efficacy of an Internet-based self-help intervention to reduce co-occurring alcohol misuse and depression symptoms in adults: study protocol of a three-arm randomised controlled trial. BMJ Open 2016;6:e011457.

41 Hodgins DC, Makarchuk K. Becoming a winner: Defeating problem gambling. Calgary, Canadá; 2002.

42 Ross L, Lepper MR, Hubbard M. Perseverance in self-perception and social perception: biased attributional processes in the Debriefing paradigm. J Pers Soc Psychol 1975;32:880-92.

43 Cunningham JA, Kypri K, McCambridge J. Exploratory randomized controlled trial evaluating the impact of a waiting list control design. BMC Med Res Methodol 2013;13:150.

44 Hodgins DC, Currie SR, el-Guebaly N. Motivational enhancement and self-help treatments for problem gambling. J Consult Clin Psychol 2001;69:50-7.

45 Hodgins DC, Currie SR, Currie G, et al. Randomized trial of brief motivational treatments for pathological gamblers: more is not necessarily better. J Consult Clin Psychol 2009;77:950-60.

46 Robinson SM, Sobell LC, Sobell MB, et al. Reliability of the Timeline Followback for cocaine, cannabis, and cigarette use. Psychol Addict Behav 2014;28:154-62.

47 Ferris JA, Wynne HJ. The Canadian problem gambling index. Ottawa, ON: Canadian Centre on Substance Abuse, 2001.

$48 \mathrm{Kim}$ SW, Grant JE, Potenza MN, et al. The gambling symptom assessment scale (G-SAS): a reliability and validity study. Psychiatry Res 2009;166:76-84

49 Kroenke K, Spitzer RL, Williams JB. The PHQ-9: validity of a brief depression severity measure. J Gen Intern Med 2001;16:606-13.

50 Arroll B, Goodyear-Smith F, Crengle S, et al. Validation of PHQ-2 and $\mathrm{PHQ}-9$ to screen for major depression in the primary care population. Ann Fam Med 2010;8:348-53.

51 Löwe B, Decker O, Müller S, et al. Validation and standardization of the generalized anxiety disorder screener (GAD-7) in the general population. Med Care 2008;46:266-74.

52 Daigre Blanco C, Ramos-Quiroga JA, Valero S, et al. Adult ADHD self-report scale (ASRS-v1.1) symptom checklist in patients with substance use disorders. Actas Esp Psiquiatr 2009;37:299-305.

53 Siegrist P, Maercker A. Deutsche Fassung Der short screening scale for DSM-IV posttraumatic stress disorder. Aktueller stand Der Validierung. Trauma und Gewalt 2010;4:208-13.

54 Kirby KN, Maraković NN. Delay-discounting probabilistic rewards: rates decrease as amounts increase. Psychon Bull Rev 1996;3:100-4.

55 Kirby KN, Petry NM, Bickel WK. Heroin addicts have higher discount rates for delayed rewards than non-drug-using controls. J Exp Psychol 1999;128:78-87.

56 Saunders JB, Aasland OG, Babor TF, et al. Development of the Alcohol Use Disorders Identification Test (AUDIT): WHO Collaborative Project on Early Detection of Persons with Harmful Alcohol Consumption--II. Addiction 1993;88:791-804.

57 Bohn MJ, Babor T, Kranzler HR. Validity of the drug abuse screening test (DAST-10) in inpatient substance abusers. Problems of drug dependence 1991;119:233-5.

58 National Institute on Drug Abuse, World Health Organization. NIDAModified ASSIST-Pre-screen v1.0, 2009. Available: http://www. drugabuse.gov/nidamed/screening/nmassist.pdf

59 Dube P, Kurt K, Bair MJ, et al. The P4 screener: evaluation of a brief measure for assessing potential suicide risk in 2 randomized effectiveness trials of primary care and oncology patients. Prim Care Companion J Clin Psychiatry 2010;12.

60 Boß L, Lehr D, Reis D, et al. Reliability and validity of assessing user satisfaction with web-based health interventions. J Med Internet Res 2016;18:e234.

61 Rozental A, Boettcher J, Andersson G, et al. Negative effects of internet interventions: a qualitative content analysis of patients experiences with treatments delivered online. Cogn Behav Ther 2015;44:223-36.

62 Buuren Svan, Groothuis-Oudshoorn K. Mice: multivariate imputation by Chained equations in R. J Stat Softw 2011;45.

63 Eysenbach G, CONSORT-EHEALTH Group. CONSORT-EHEALTH: improving and standardizing evaluation reports of web-based and mobile health interventions. J Med Internet Res 2011;13:e126. 